\title{
Association between dietary fat and fat subtypes with the risk of breast cancer in an Iranian population: a case-control study
}

\author{
Maedeh Mozafarinia', Bahareh Sasanfar ${ }^{1,2,3}$, Fatemeh Toorang ${ }^{1,4}$, Amin Salehi-Abargouei ${ }^{2,3}$ and \\ Kazem Zendehdel ${ }^{1,5,6,7^{*}}$
}

\begin{abstract}
Aim: To examine the relationship between dietary fat intake and breast cancer (BC) development.

Method: This case-control study included 473 women with breast cancer (pathologically confirmed) and 501 healthy subjects matched by age and residency. Dietary intakes of different types and sources of fatty acids were assessed using a validated food frequency questionnaire. The association between dietary fats and odds of BC was assessed using a logistic regression model in crude and multivariable-adjusted models. $P$ values below 0.05 were regarded as statistically significant.

Results: Participants' age and body mass index were $44.0 \pm 10.8$ years and $28.4 \pm 5.6 \mathrm{~kg} / \mathrm{m}^{2}$, respectively. Individuals with the highest quartile of total fat intake and polyunsaturated fatty acid (PUFA) intake were 1.50 times more at risk to develop $\mathrm{BC}$ than others. A positive significant association was observed between animal fat (Q4 vs. Q1, OR= $1.89,95 \% \mathrm{Cl}=0.93-3.81$ ), saturated fatty acid (SFA) (Q4 vs. Q1, $\mathrm{OR}=1.70,95 \% \mathrm{Cl}=0.88-3.30)$, monounsaturated fatty acid (MUFA) (Q4 vs. Q1 OR=1.85, $95 \% \mathrm{Cl}=0.95-3.61$ ) and PUFA intake (Q4 vs. Q1, OR=2.12, $95 \% \mathrm{Cl}=1.05-$ 4.27) with $B C$ risk in postmenopausal women. However, there was no association in premenopausal women.

Conclusions: Total dietary fat and its subtypes might increase the risk of $B C$, especially in postmenopausal women. This observational study confirms the role of dietary fat in breast cancer development. Intervention studies involving different estrogen receptor subgroups are needed.
\end{abstract}

Keywords: Fatty acids, Dietary fat, Polyunsaturated fatty acid, Animal fat saturated fatty acid, Monounsaturated fatty acid, Breast cancer, Neoplasms, Postmenopausal, Premenopausal

\section{Introduction}

Breast cancer $(\mathrm{BC})$ is the most prevalent cancer in women and the second foremost reason for cancerrelated deaths in developed countries after lung cancer [1]. It is predicted that more than 2.1 million new $\mathrm{BC}$ cases occur worldwide annually, expressing over

\footnotetext{
* Correspondence: kzendeh@tums.ac.ir

${ }^{1}$ Cancer Research Center, Cancer Institute of Iran, Tehran University of Medical Sciences, Tehran, Iran

${ }^{5}$ Cancer Biology Research Center, Cancer Institute of Iran, Tehran University of Medical Sciences, I.R., Tehran, Iran

Full list of author information is available at the end of the article
}

$24.2 \%$ of malignancies in women [2]. Its incidence and mortality rates are higher in developed countries. The estimated Age Standard Rate (ASR) for breast cancer is estimated to be 35.8 per 100,000 women in 2020 and the disease is the third cause of death among Iranian women [3].

In addition to age, genetic and reproductive factors, other determinants like overweight or obesity, lack of physical activity, using alcohol and smoking as modifiable risk factors have been linked to $\mathrm{BC}[4,5]$. The role of diet has been shown as an important contributing 
factor to this condition. Dietary fat intake has long been hypothesized to increase $\mathrm{BC}$ risk; however, the findings were discrepant up to now $[6,7]$. Some studies have only examined the total fat intake in association with $\mathrm{BC}$ risk, while others performed distinct analyses based on main fat subtypes. Some observational studies have shown a weak [8-13] or no significant association [14-18] between high fat intake and the risk of BC. Similar to these findings, no correlation was reported between $n-3$ and n-6 polyunsaturated (PUFA) fat intake and BC risk among Chinese women [19]. In contrast, a positive association was observed in some studies [10, 20-22]. Also, two studies [14, 15] found no association for eicosapentaenoic acid (EPA) and docosahexaenoic acid (DHA) as the two key n-3 PUFAs. However, Ouldamer et al. revealed that high dietary intake of EPA and DHA is associated with a $25 \%$ decrease in BC risk [16]. Two case-control studies showed that animal fat intake was not associated with BC risk in premenopausal [17] and postmenopausal [18] women; however, significant associations were reported only among premenopausal women in some other observational studies [23-25].

Overall, a few studies have assessed the association between various types of fat intake and BC risk in the Middle-Eastern countries, as dietary intake and environmental issues are considerably different in this region (high amounts of carbohydrates, refined grains, or animal fats) [26]. Therefore, we aimed to examine if dietary total fat, animal fat, and different fatty acids intake are associated with the risk of BC in Iranian women.

\section{Methods and materials}

\section{Study design and population}

This was a case-control study performed from May 2014 to April 2016. Women aged $19-80$ years $(n=486)$ with $\mathrm{BC}$ verified by pathological study entered the trial. All cases were recruited from patients referred to the Cancer Institute, situated at Imam Khomeini Complex in Tehran. Participants did not have any long-term dietary restrictions and history of any other cancers whom was new breast cancer cases. Controls $(n=516)$ were selected from healthy women who were relatives and friends of patients without cancer who were referred to Imam Khomeini Hospital Complex, Tehran, Iran. Controls were matched regarding the place of residence (Tehran province, other provinces) and age (5-year groups). Cases and controls were selected based on convenience sampling. According to the study design, participants who had either no response to more than 70 items of the food frequency questionnaire (FFQ) or a reported total energy intake of more than 5500 or less than $800 \mathrm{kcal} / \mathrm{d}(\mathrm{n}=116)$ were excluded. Ultimately, 473 cases and 501 controls entered the final analysis. Written informed consent was obtained from all participants.
The study protocol was approved by the Bioethics Committee of Tehran University of Medical Sciences, Tehran, Iran (Ethics code: 93-03-51-27113).

Dietary intake assessment. The usual intake of 168 food items in the last year was assessed using a semiquantitative FFQ by interviewing trained investigators. The reliability and validity of this FFQ were investigated by comparing data from two similar FFQ completed one year apart according to previous investigations [27, 28]. The FFQ used in this study included foods that Iranians usually consume. Participants were interviewed by a trained dietitian to report their food consumption (daily, weekly, monthly, or yearly). They also asked all participants to report their food consumption available only in specific seasons. For each food item, the reported frequency of consumption was converted to frequency per day and was multiplied by the standard portion size (grams) using household measures [29] to calculate grams per day. Then the daily energy and nutrient intake were calculated using the United States Department of Agriculture (USDA) food composition database modified for Iranian foods [30]. The daily nutrient intakes from food items were summed up to calculate the total daily intakes.

Assessment of other variables. BMI was calculated as weight in kilograms divided by height in meters squared. Physical activity assessment was done through the Global Physical Activity Questionnaire (GPAQ) validated for adults [31]. This questionnaire includes 16 items that quantify an average weekly physical activity level. The World Health Organization (WHO) developed the GPAQ to estimate activities in a typical week among these four domains; sedentary lifestyle, job-related activities, recreation, sports, and transportation. The data were then analyzed using the GPAQ guide [32]. The duration and frequency of physical activity (MET-h/wk) over a typical week were recorded. Moreover, a face-toface interview was performed and other information including marital status, family history, alcohol consumption or tobacco use, menarche age, pregnancy, and obstetrics history (hormone therapy, and contraceptive use, infertility, menopause, etc.) were recorded.

\section{Statistical analysis}

Data were analyzed according to menopausal status or in all participants as a whole. Total energy intake was adjusted as a confounding factor using the residual method [33]. Thereafter, subjects were categorized according to quartiles of dietary fatty acid intake. ANOVA, $\mathrm{t}$-test, or $\mathrm{Chi}^{2}$ test was used where appropriate. Also, multivariable logistic regression was performed to evaluate any correlation between dietary fat and fatty acid with the development of BC. In the first model, adjustments were made for energy intake and age. In the 
multivariable model, further adjustments were considered for cigarette smoking, physical activity, alcohol consumption, BC family history, marital status, educational level, parity, and BMI. The first quartile of fat intake was considered as the reference group. All the analyses were performed using STATA version 14 (State Corp.). P values $<0.05$ were considered as statistically significant.

\section{Results}

The study included 473 cases (309 pre- and 158 postmenopausal women) and 501 controls (326 pre- and 165 postmenopausal women). Participants' characteristics are depicted in Table 1.

Patients with $\mathrm{BC}$ were older ( 45.8 vs. 43.9 years), had a family history of $\mathrm{BC}$ more frequently (46 vs. $7 \%$ ), and had lower BMI (28.1 vs. $28.8 \mathrm{~kg} / \mathrm{m} 2)$ compared with the control subjects. Also, they had lower physical activity (22.7 vs. 29.4 MET h/wk). Besides, they were less likely to use oral contraceptives (53 vs. $61.2 \%$ ) postmenopausal hormones $(0.42$ vs. $2 \%)$ or drink alcohol (2.5 vs. $5.9 \%)$ than controls.

Table 1 Baseline characteristics of the study participants

\begin{tabular}{|c|c|c|c|}
\hline & $\begin{array}{l}\text { Case } \\
(n=473)\end{array}$ & $\begin{array}{l}\text { Control } \\
(n=501)\end{array}$ & p-value \\
\hline Age (years) & $45.8 \pm 10.3$ & $43.9 \pm 11.2$ & 0.002 \\
\hline BMI (kg/m2) & $28.0 \pm 5.1$ & $28.8 \pm 6.0$ & 0.01 \\
\hline Physical activity (MET-h/week) & $22.7 \pm 40.2$ & $29.4 \pm 43.9$ & 0.006 \\
\hline Age at menarche (years) & $13.0 \pm 2.5$ & $12.9 \pm 2.7$ & 0.28 \\
\hline \multicolumn{4}{|l|}{ Menopausal status (\%) } \\
\hline Premenopausal & $309(66.1)$ & $326(66.4)$ & 0.94 \\
\hline Postmenopausal & $158(33.8)$ & 165 (33.6) & \\
\hline \multicolumn{4}{|l|}{ Educational level (\%) } \\
\hline Un university & $394(84.3)$ & $411(84.0)$ & 0.89 \\
\hline University & $73(15.6)$ & $78(15.9)$ & \\
\hline \multicolumn{4}{|l|}{ Marital status (\%) } \\
\hline Married & $437(93.7)$ & $462(94.2)$ & 0.74 \\
\hline Unmarried/divorced/widowed & $29(6.2)$ & $28(5.7)$ & \\
\hline Family history of breast cancer (\%) & $46(9.8)$ & $7(1.4)$ & $<0.001$ \\
\hline Oral contraceptive use (\%) & $244(53.0)$ & $259(61.2)$ & 0.01 \\
\hline Current smoker (\%) & $18(3.8)$ & $25(5.1)$ & 0.34 \\
\hline Alcohol use (\%) & $12(2.5)$ & $30(5.9)$ & 0.008 \\
\hline Postmenopausal hormone use (\%) & $2(0.42)$ & $10(2.00)$ & 0.02 \\
\hline \multicolumn{4}{|l|}{ Parity } \\
\hline Nulliparous/missing & $210(44.1)$ & $215(42.9)$ & 0.90 \\
\hline 1 & $42(8.8)$ & $51(10.1)$ & \\
\hline $2-3$ & $149(31.3)$ & $155(30.9)$ & \\
\hline$\geq 4$ & 75 (15.7) & 80 (15.9) & \\
\hline
\end{tabular}

$\mathrm{X} 2$ Test for ordinal qualitative variables and t-test for continuous variables Abbreviation: BMI, Body mass index
As shown in Table 2, patients had a higher intake of total fat (21.9 vs. $27.9 \mathrm{~g}, P=0.02)$, SFA (9.1 vs. $8.6 \mathrm{~g}, P<$ 0.01 ), and PUFAs (8.7 vs. $8.3, P=0.05$ ), and a lower intake of oleic acid (6.07 vs. $6.35, P=0.05$ ) compared with the controls (Fig. 1). The stratification by menopausal status showed that premenopausal women with cancer had a significantly higher intake of energy (2769 vs. $2641 \mathrm{kcal} /$ day, $P=0.05)$ and SFA $(9.2$ vs. $8.7 \mathrm{~g}, P=0.01)$ than controls. Also, SFA (9 vs. $8.4 \mathrm{~g}, P=0.04$ ) intake was higher in postmenopausal women with cancer compared to controls.

The estimated OR and $95 \%$ CIs for BC according to quartiles of fat intake are shown in Table 3. Total fat intake was positively associated with the odds of $\mathrm{BC}$ in all participants as a whole. After confounding factors were controlled, women with highest total fat intakes had 1.50 times more risk to develop $\mathrm{BC}$ than those with lowest intakes. Besides, compared with women in the first and fourth quartiles, participants in the highest quartile of PUFA intake had a 1.50-time more risk to have BC (Fig. 2).

In a subgroup analysis based on menopausal status, a positive association was found between animal fat (Q4 vs. $\mathrm{Q} 1 \mathrm{OR}=1.89,95 \% \mathrm{CI}=0.93-3.81)$, SFA (Q4 vs. Q1 $\mathrm{OR}=1.70,95 \% \mathrm{CI}=0.88-3.30)$, MUFA $(\mathrm{Q} 4$ vs. $\mathrm{Q} 1 \mathrm{OR}=$ $1.85,95 \% \mathrm{CI}=0.95-3.61)$ and PUFA intake (Q4 vs. Q1 $\mathrm{OR}=2.12,95 \% \mathrm{CI}=1.05-4.27$ ), with the risk of $\mathrm{BC}$ in postmenopausal women. Nonetheless, no association was found in premenopausal women.

\section{Discussion}

The dietary total fat intake was positively associated with $\mathrm{BC}$ risk in all participants who entered the current investigation. Also, higher PUFA intake was related to an increased possibility of $\mathrm{BC}$. However, the associations were significant only among postmenopausal women after the stratification of analyses based on menopausal status. These results indicate that a higher intake of animal fat, SFA, MUFA, and PUFA was associated with a higher risk of $\mathrm{BC}$ in postmenopausal women. Moreover, a direct association was observed between total fat and PUFA intake and $\mathrm{BC}$ risk in all participants as a whole. On the contrary, the Nurses' Health Study found no association between any fat subtypes and BC [34]. Also, a metaanalysis reported no correlation between breast cancer risk and dietary total fat, SFA, MUFA, and PUFA intake [35]. This discrepancy might be due to different study populations or designs, different types of studied fatty acids, or possible measurement bias.

A significant positive association was also reported between dietary fat subtypes and the risk of $\mathrm{BC}$ in postmenopausal women, but there was no association in premenopausal women. In contrast to the current 
Table $\mathbf{2}$ dietary fats intakes of the participants ${ }^{a}$

\begin{tabular}{|c|c|c|c|}
\hline & Case & Control & \\
\hline & Mean \pm SD & Mean \pm SD & P value \\
\hline \multicolumn{4}{|c|}{ All women (473 case, 501 control) } \\
\hline Energy (kcal/d) & $2673.3 \pm 986.5$ & $2619.7 \pm 975.6$ & 0.19 \\
\hline Total fat & $29.1 \pm 9.6$ & $27.9 \pm 9.1$ & 0.02 \\
\hline Animal fat & $22.6 \pm 9.9$ & $21.7 \pm 9.0$ & 0.06 \\
\hline Vegetable fat & $6.4 \pm 4.0$ & $6.2 \pm 3.4$ & 0.18 \\
\hline Total SFA & $9.1 \pm 3.3$ & $8.6 \pm 2.9$ & 0.007 \\
\hline Myristic acid (14:0) & $0.62 \pm 0.34$ & $0.63 \pm 0.31$ & 0.41 \\
\hline Palmitic acid (16:0) & $3.17 \pm 1.1$ & $3.19 \pm 1.0$ & 0.40 \\
\hline Stearic acid (18:0) & $1.23 \pm 0.53$ & $1.23 \pm 0.49$ & 0.44 \\
\hline Total MUFA & $8.5 \pm 2.9$ & $8.3 \pm 2.8$ & 0.17 \\
\hline Palmitoleic acid (16:1n-7) & $0.20 \pm 0.098$ & $0.21 \pm 0.095$ & 0.13 \\
\hline Oleic acid (18:1n-9) & $6.07 \pm 2.7$ & $6.35 \pm 2.7$ & 0.05 \\
\hline Total PUFA & $8.7 \pm 4.0$ & $8.3 \pm 3.9$ & 0.05 \\
\hline \multicolumn{4}{|l|}{ n-3 PUFA } \\
\hline EPA (20:5n-3) & $0.011 \pm 0.02$ & $0.010 \pm 0.01$ & 0.25 \\
\hline DPA (22:5n-3) & $0.003 \pm 0.003$ & $0.003 \pm 0.004$ & 0.44 \\
\hline DHA (22:6n-3) & $0.01 \pm 0.03$ & $0.01 \pm 0.02$ & 0.35 \\
\hline \multicolumn{4}{|l|}{ n-6 PUFA } \\
\hline Linoleic acid (18:2n-6) & $5.3 \pm 2.9$ & $5.1 \pm 2.5$ & 0.23 \\
\hline Arachidonic acid (20:4n-6) & $0.02 \pm 0.01$ & $0.03 \pm 0.02$ & 0.10 \\
\hline Total Cholesterol & $62.0 \pm 30.6$ & $62.9 \pm 28.2$ & 0.32 \\
\hline \multicolumn{4}{|c|}{ Premenopausal women (309 case, 326 control) } \\
\hline Energy (kcal/d) & $2769.3 \pm 990.5$ & $2641.1 \pm 995.6$ & 0.05 \\
\hline Total fat & $29.3 \pm 9.4$ & $28.5 \pm 9.1$ & 0.12 \\
\hline Animal fat & $22.8 \pm 9.8$ & $22.0 \pm 9.2$ & 0.13 \\
\hline Vegetable fat & $6.5 \pm 3.6$ & $6.4 \pm 3.7$ & 0.47 \\
\hline Total SFA & $9.2 \pm 3.2$ & $8.7 \pm 2.8$ & 0.01 \\
\hline Myristic acid (14:0) & $0.63 \pm 0.33$ & $0.61 \pm 0.29$ & 0.28 \\
\hline Palmitic acid (16:0) & $3.2 \pm 1.0$ & $3.1 \pm 0.99$ & 0.44 \\
\hline Stearic acid (18:0) & $1.2 \pm 0.52$ & $1.2 \pm 0.50$ & 0.42 \\
\hline Total MUFA & $8.6 \pm 2.9$ & $8.5 \pm 2.8$ & 0.32 \\
\hline Palmitoleic acid (16:1n-7) & $0.20 \pm 0.09$ & $0.20 \pm 0.09$ & 0.48 \\
\hline Oleic acid (18:1n-9) & $6.1 \pm 2.7$ & $6.4 \pm 2.8$ & 0.07 \\
\hline Total PUFA & $8.8 \pm 3.9$ & $8.7 \pm 3.9$ & 0.33 \\
\hline \multicolumn{4}{|l|}{ n-3 PUFA } \\
\hline EPA (20:5n-3) & $0.01 \pm 0.02$ & $0.01 \pm 0.01$ & 0.35 \\
\hline DPA (22:5n-3) & $0.003 \pm 0.003$ & $0.003 \pm 0.003$ & 0.26 \\
\hline DHA (22:6n-3) & $0.01 \pm 0.02$ & $0.01 \pm 0.01$ & 0.38 \\
\hline \multicolumn{4}{|l|}{ n-6 PUFA } \\
\hline Linoleic acid (18:2n-6) & $5.2 \pm 2.7$ & $5.3 \pm 2.7$ & 0.42 \\
\hline Arachidonic acid (20:4n-6) & $0.03 \pm 0.02$ & $0.03 \pm 0.02$ & 0.33 \\
\hline Total Cholesterol & $63.9 \pm 29.8$ & $63.3 \pm 27.6$ & 0.39 \\
\hline
\end{tabular}

Postmenopausal (158 case, 165 control) 
Table 2 dietary fats intakes of the participants ${ }^{a}$ (Continued)

\begin{tabular}{|c|c|c|c|}
\hline & Case & Control & \\
\hline Energy & $2545.6 \pm 951.5$ & $2583.1 \pm 959.0$ & 0.36 \\
\hline Total fat & $28.8 \pm 9.9$ & $26.6 \pm 8.9$ & 0.01 \\
\hline Animal fat & $22.5 \pm 10.1$ & $20.9 \pm 8.9$ & 0.06 \\
\hline Vegetable fat & $6.2 \pm 4.3$ & $5.7 \pm 2.9$ & 0.09 \\
\hline Total SFA & $9.0 \pm 3.5$ & $8.4 \pm 3.1$ & 0.04 \\
\hline Myristic acid (14:0) & $0.62 \pm 0.36$ & $0.66 \pm 0.33$ & 0.15 \\
\hline Palmitic acid (16:0) & $3.1 \pm 1.1$ & $3.1 \pm 1.0$ & 0.31 \\
\hline Stearic acid (18:0) & $1.16 \pm 0.55$ & $1.19 \pm 0.48$ & 0.32 \\
\hline Total MUFA & $8.5 \pm 2.9$ & $8.0 \pm 2.8$ & 0.09 \\
\hline Palmitoleic acid (16:1n-7) & $0.20 \pm 0.1$ & $0.22 \pm 0.09$ & 0.06 \\
\hline Oleic acid (18:1n-9) & $5.9 \pm 2.7$ & $6.1 \pm 2.7$ & 0.20 \\
\hline Total PUFA & $8.5 \pm 4.1$ & $7.5 \pm 3.7$ & 0.01 \\
\hline \multicolumn{4}{|l|}{ n-3 PUFA } \\
\hline EPA (20:5n-3) & $0.01 \pm 0.02$ & $0.01 \pm 0.02$ & 0.25 \\
\hline DPA (22:5n-3) & $0.003 \pm 0.003$ & $0.003 \pm 0.004$ & 0.22 \\
\hline DHA (22:6n-3) & $0.022 \pm 0.03$ & $0.021 \pm 0.02$ & 0.34 \\
\hline \multicolumn{4}{|l|}{ n-6 PUFA } \\
\hline Linoleic acid (18:2n-6) & $5.1 \pm 2.8$ & $4.7 \pm 2.2$ & 0.09 \\
\hline Arachidonic acid (20:4n-6) & $0.02 \pm 0.01$ & $0.03 \pm 0.02$ & 0.10 \\
\hline Total Cholesterol & $59.1 \pm 32.1$ & $61.8 \pm 29.5$ & 0.21 \\
\hline
\end{tabular}

${ }^{a}$ All value were $\%$ energy intake, All quantities for fatty acids were reported as grams

findings, two studies $[23,36]$ reported a significant positive association for animal fat in premenopausal women. Fatty acids composition of animal and vegetable origin are different, which might have varied effects on $\mathrm{BC}$ development [25]. In another analysis in premenopausal women, higher animal fat intake significantly predicted a higher mammographic density which in turn, increases the risk of $\mathrm{BC}$ [37]. However, in one retrospective study, hyperlipidemia was associated with higher breast density in premenopausal women [38].

In the present study, SFA and MUFA intake also increased BC risk in postmenopausal women. These

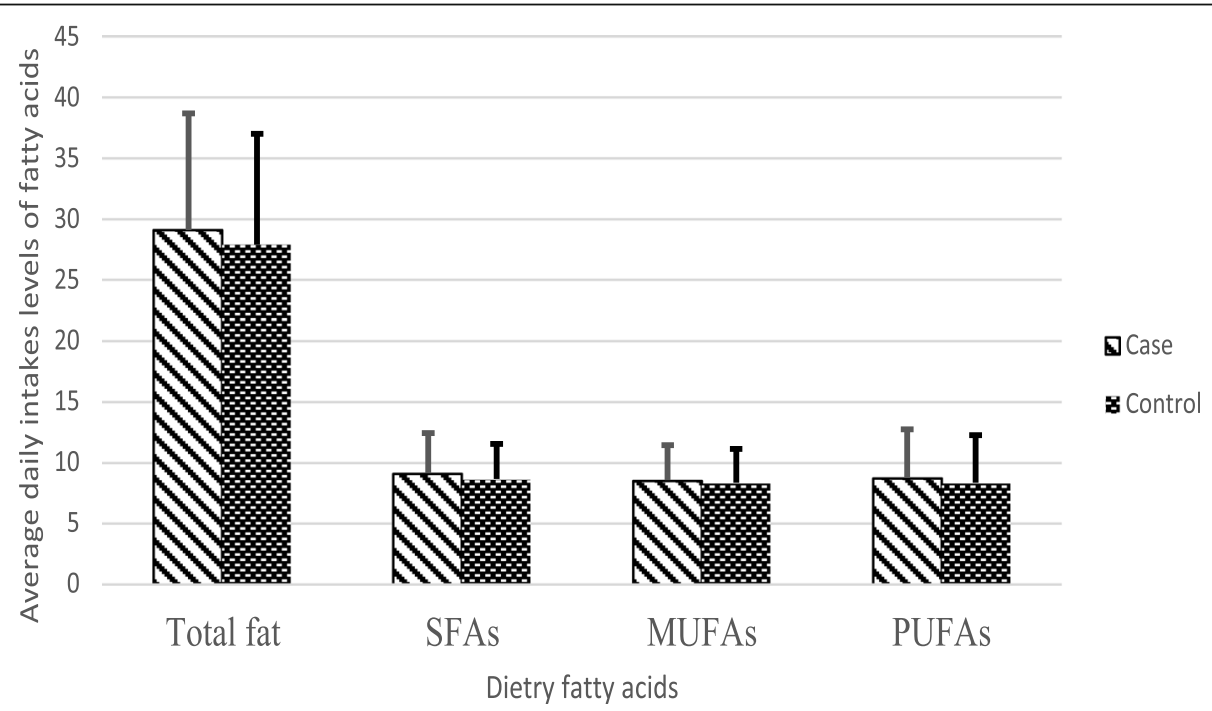

Fig. 1 Mean (SD) energy adjusted values for dietary total fat, saturated (SFAs), mono-unsaturated (MUFAs) and poly-unsaturated (PUFAs) fatty acids in participants with and without breast cancer 
Table 3 Odds ratio (OR) and $95 \%$ confidence intervals (Cl) for breast cancer according to quartile of fat intake in women

\begin{tabular}{|c|c|c|c|c|c|}
\hline & \multicolumn{5}{|c|}{ Quartile of intake } \\
\hline & 1 & 2 & 3 & 4 & $P$ value \\
\hline & \multicolumn{5}{|l|}{ Total fat } \\
\hline All women & $107 / 126$ & $105 / 124$ & $125 / 125$ & $133 / 126$ & \\
\hline Age and energy adjusted OR & 1 & $1.07(0.72-1.57)$ & $1.36(0.92-2.01)$ & $1.40(0.97-2.02)$ & 0.03 \\
\hline Multivariable OR & 1 & $1.11(0.74-1.67)$ & $1.44(0.95-2.16)$ & $1.50(1.02-2.20)$ & 0.01 \\
\hline Premenopausal women & $68 / 80$ & $71 / 67$ & $84 / 91$ & $81 / 88$ & \\
\hline Age and energy adjusted OR & 1 & $1.46(0.89-2.40)$ & $1.40(0.86-2.26)$ & $1.27(0.80-2.00)$ & 0.4 \\
\hline Multivariable OR & 1 & $1.53(0.92-2.57)$ & $1.43(0.86-2.39)$ & $1.31(0.81-2.12)$ & 0.36 \\
\hline Postmenopausal women & $36 / 45$ & $32 / 55$ & $40 / 32$ & $49 / 33$ & \\
\hline Age and energy adjusted OR & 1 & $0.66(0.34-1.26)$ & $1.40(0.71-2.76)$ & $1.88(1.00-3.54)$ & 0.008 \\
\hline \multirow[t]{2}{*}{ Multivariable OR } & 1 & $0.66(0.33-1.32)$ & $1.62(0.78-3.34)$ & $2.16(1.11-4.22)$ & 0.003 \\
\hline & \multicolumn{5}{|c|}{ Animal fat } \\
\hline All women & $107 / 126$ & $120 / 125$ & $118 / 123$ & $126 / 127$ & \\
\hline Age and energy adjusted OR & 1 & $1.19(0.81-1.75)$ & $1.28(0.86-1.89)$ & $1.28(0.88-1.83)$ & 0.19 \\
\hline Multivariable OR & 1 & $1.10(0.74-1.65)$ & $1.38(0.92-2.08)$ & $1.28(0.87-1.88)$ & 0.12 \\
\hline Premenopausal women & $70 / 84$ & $76 / 76$ & $78 / 73$ & $81 / 93$ & \\
\hline Age and energy adjusted OR & 1 & $1.36(0.84-2.19)$ & $1.50(0.92-2.46)$ & $1.14(0.73-1.78)$ & 0.59 \\
\hline Multivariable OR & 1 & $1.26(0.76-2.08)$ & $1.53(0.91-2.57)$ & $1.11(0.69-1.77)$ & 0.62 \\
\hline Postmenopausal women & $33 / 41$ & $42 / 48$ & $39 / 45$ & $43 / 31$ & \\
\hline Age and energy adjusted OR & 1 & $0.99(0.52-1.88)$ & $0.99(0.50-1.92)$ & $1.69(0.87-3.28)$ & 0.12 \\
\hline \multirow[t]{2}{*}{ Multivariable OR } & 1 & $0.93(0.47-1.86)$ & $1.19(0.59-2.42)$ & $1.89(0.93-3.81)$ & 0.05 \\
\hline & \multicolumn{5}{|c|}{ Vegetable fat } \\
\hline All women & $119 / 126$ & $142 / 123$ & $85 / 123$ & $130 / 129$ & \\
\hline Age and energy adjusted OR & 1 & $1.34(0.92-1.95)$ & $0.80(0.53-1.22)$ & $1.24(0.86-1.78)$ & 0.72 \\
\hline Multivariable OR & 1 & $1.41(0.95-2.08)$ & $0.90(0.59-1.39)$ & $1.30(0.89-1.91)$ & 0.51 \\
\hline Premenopausal women & $77 / 76$ & $89 / 77$ & $55 / 80$ & $88 / 93$ & \\
\hline Age and energy adjusted OR & 1 & $1.30(0.81-2.09)$ & $0.83(0.50-1.40)$ & $1.13(0.72-1.77)$ & 0.97 \\
\hline Multivariable OR & 1 & $1.45(0.88-2.39)$ & $0.92(0.53-1.59)$ & $1.20(0.74-1.94)$ & 0.87 \\
\hline Postmenopausal women & $41 / 50$ & $49 / 42$ & $28 / 42$ & $40 / 31$ & \\
\hline Age and energy adjusted OR & 1 & $1.34(0.71-2.52)$ & $0.73(0.436-1.47)$ & $1.56(0.82-2.95)$ & 0.45 \\
\hline \multirow[t]{2}{*}{ Multivariable OR } & 1 & $1.29(0.66-2.51)$ & $0.82(0.39-1.71)$ & $1.68(0.85-3.31)$ & 0.29 \\
\hline & \multicolumn{5}{|c|}{ Total SFA } \\
\hline All women & $106 / 126$ & $108 / 123$ & $131 / 124$ & $124 / 128$ & \\
\hline Age and energy adjusted OR & 1 & $1.08(0.74-1.59)$ & $1.46(0.99-2.14)$ & $1.27(0.88-1.83)$ & 0.09 \\
\hline Multivariable OR & 1 & $1.17(0.78-1.74)$ & $1.55(1.04-2.32)$ & $1.28(0.87-1.88)$ & 0.11 \\
\hline Premenopausal women & $67 / 79$ & $73 / 77$ & $85 / 82$ & $78 / 88$ & \\
\hline Age and energy adjusted OR & 1 & $1.15(0.72-1.86)$ & $1.53(0.95-2.48)$ & $1.17(0.74-1.86)$ & 0.34 \\
\hline Multivariable OR & 1 & $1.26(0.77-2.08)$ & $1.50(0.90-2.47)$ & $1.14(0.71-1.85)$ & 0.52 \\
\hline Postmenopausal women & $36 / 46$ & $33 / 45$ & $43 / 37$ & $45 / 37$ & \\
\hline Age and energy adjusted OR & 1 & $0.87(0.45-1.67)$ & $1.40(0.74-2.67)$ & $1.56(0.83-2.92)$ & 0.07 \\
\hline \multirow[t]{2}{*}{ Multivariable OR } & 1 & $0.96(0.48-1.93)$ & $1.75(0.88-3.46)$ & $1.70(0.88-3.30)$ & 0.04 \\
\hline & \multicolumn{5}{|c|}{ Total MUFA } \\
\hline All women & 109/126 & $114 / 124$ & $120 / 124$ & $131 / 127$ & \\
\hline Age and energy adjusted OR & 1 & $1.14(0.78-1.68)$ & $1.27(0.86-1.88)$ & $1.29(0.90-1.86)$ & 0.13 \\
\hline
\end{tabular}


Table 3 Odds ratio (OR) and $95 \%$ confidence intervals (Cl) for breast cancer according to quartile of fat intake in women (Continued)

\begin{tabular}{|c|c|c|c|c|c|}
\hline \multirow[b]{2}{*}{ Multivariable OR } & \multicolumn{5}{|c|}{ Quartile of intake } \\
\hline & 1 & $1.20(0.81-1.79)$ & $1.32(0.88-1.98)$ & $1.34(0.92-1.96)$ & 0.11 \\
\hline Premenopausal women & $70 / 82$ & $81 / 77$ & $78 / 79$ & $78 / 88$ & \\
\hline Age and energy adjusted OR & 1 & $1.48(0.92-2.38)$ & $1.56(0.95-2.55)$ & $1.17(0.74-1.84)$ & 0.55 \\
\hline Multivariable OR & 1 & $1.51(0.92-2.48)$ & $1.53(0.91-2.58)$ & $1.19(0.74-1.91)$ & 0.57 \\
\hline Postmenopausal women & $36 / 42$ & $31 / 46$ & $39 / 42$ & $52 / 35$ & \\
\hline Age and energy adjusted OR & 1 & $0.68(0.35-1.34)$ & $0.98(0.51-1.89)$ & $1.70(0.91-3.18)$ & 0.04 \\
\hline \multirow[t]{2}{*}{ Multivariable OR } & 1 & $0.74(0.36-1.50)$ & $1.09(0.54-2.20)$ & $1.85(0.95-3.61)$ & 0.03 \\
\hline & \multicolumn{5}{|c|}{ Total PUFA } \\
\hline All women & $98 / 126$ & $121 / 123$ & $130 / 124$ & $123 / 128$ & \\
\hline Age and energy adjusted OR & 1 & $1.33(0.9-1.95)$ & $1.54(1.05-2.26)$ & $1.36(0.94-1.97)$ & 0.08 \\
\hline Multivariable OR & 1 & $1.43(0.96-2.14)$ & $1.70(1.13-2.55)$ & $1.50(1.02-2.22)$ & 0.03 \\
\hline Premenopausal women & $67 / 76$ & $73 / 72$ & $82 / 86$ & $84 / 92$ & \\
\hline Age and energy adjusted OR & 1 & $1.29(0.80-2.10)$ & $1.31(0.81-2.11)$ & $1.16(0.74-1.83)$ & 0.56 \\
\hline Multivariable OR & 1 & $1.45(0.87-2.40)$ & $1.48(0.90-2.45)$ & $1.28(0.79-2.07)$ & 0.37 \\
\hline Postmenopausal women & $30 / 49$ & $44 / 49$ & $47 / 35$ & $36 / 32$ & \\
\hline Age and energy adjusted OR & 1 & $1.42(0.74-2.72)$ & $2.11(1.08-4.15)$ & $1.90(0.97-3.70)$ & 0.02 \\
\hline \multirow[t]{2}{*}{ Multivariable OR } & 1 & $1.41(0.70-2.85)$ & $2.42(1.17-5.01)$ & $2.12(1.05-4.27)$ & 0.01 \\
\hline & \multicolumn{5}{|c|}{ Total Cholesterol } \\
\hline All women & $132 / 126$ & $110 / 124$ & $117 / 125$ & $116 / 126$ & \\
\hline Age and energy adjusted OR & 1 & $0.94(0.65-1.36)$ & $1.02(0.70-1.49)$ & $0.98(0.68-1.40)$ & 0.96 \\
\hline Multivariable OR & 1 & $1.02(0.69-1.51)$ & $1.08(0.72-1.60)$ & $1.03(0.71-1.52)$ & 0.79 \\
\hline Premenopausal women & $74 / 76$ & $71 / 82$ & $80 / 89$ & $83 / 79$ & \\
\hline Age and energy adjusted OR & 1 & $1.04(0.65-1.67)$ & $1.12(0.70-1.80)$ & $1.26(0.80-2.01)$ & 0.27 \\
\hline Multivariable OR & 1 & $1.09(0.66-1.80)$ & $1.19(0.72-1.96)$ & $1.29(0.79-2.09)$ & 0.27 \\
\hline Postmenopausal women & $54 / 49$ & $38 / 39$ & $33 / 32$ & $33 / 45$ & \\
\hline Age and energy adjusted OR & 1 & $0.82(0.44-1.50)$ & $0.89(0.46-1.69)$ & $0.65(0.35-1.18)$ & 0.20 \\
\hline Multivariable OR & 1 & $1.02(0.54-1.95)$ & $0.91(0.46-1.80)$ & $0.75(0.40-1.41)$ & 0.35 \\
\hline
\end{tabular}

Multivariable model: additionally, adjusted for cigar smoking, marital status, alcohol consumption, physical activity, education, family history of breast cancer, parity, and BMI

SFA: saturated fatty acids, MUFA: monounsaturated fatty acids, PUFA: polyunsaturated fatty acids

All quantities for fatty acids were reported as grams

findings regarding SFA were similar to some investigations that showed an increase in $\mathrm{BC}$ risk in postmenopausal women $[39,40]$. However, Hunter, D. J. et al. reported no association between SFA intake and breast cancer after pooling 7 prospective cohorts [41]. It is proposed that a fatrich diet is positively related to insulin resistance [42], which is probably involved in postmenopausal $\mathrm{BC}$ risk enhancement. Moreover, SFAs may increase the risk of insulin resistance and affect mammary tumorigenesis [43]. Besides, insulin resistance is associated with increased proinflammatory cytokines and decreased adiponectin levels, which could increase the probability of $\mathrm{BC}$ development in postmenopausal women [44]. A recent meta-analysis also revealed that low levels of adiponectin might increase $\mathrm{BC}$ risk in women experiencing menopause [45].
Moreover, in this study, there was a positive association between a higher intake of MUFA and the risk of $\mathrm{BC}$ in postmenopausal women. In line with the present study, in two observational studies, BC risk was directly correlated with MUFA intake [46, 47]. On the other hand, two other observational studies stated a protective effect of MUFA intake in BC development [48, 49]. These discrepancies may be due to the mechanisms triggered by oleic acid.

Stearoyl-CoA desaturase-1 (SCD1) enzyme is an important controller of fatty acid configuration in mammalian cells and plays a role in stearic acid to oleic acid conversion. In tumoral cells, SCD1 plays as a key regulator for lipogenesis able to enhance the activity of several oncogenic signaling pathways like Akt and PKC, which 


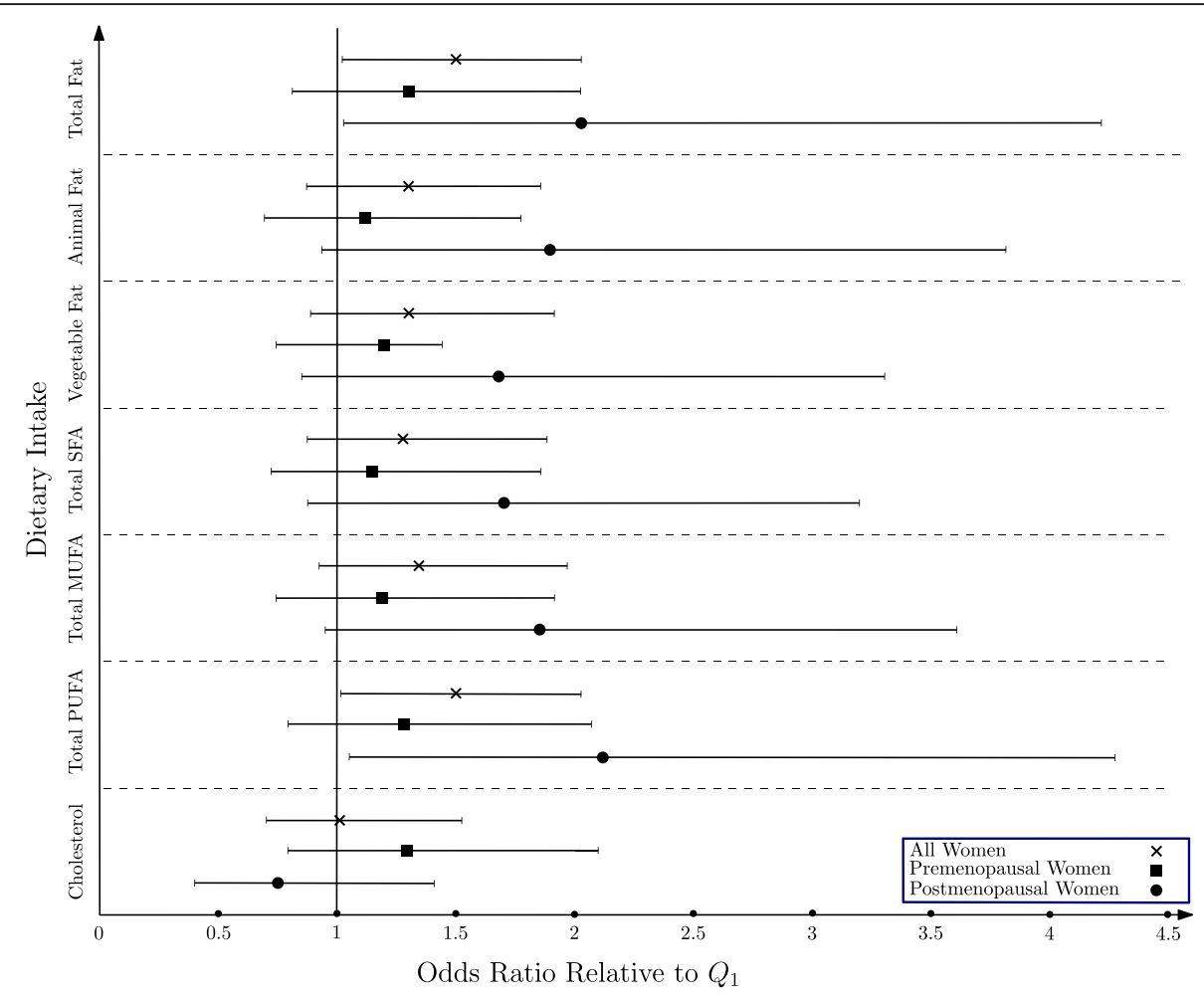

Fig. 2 Odds ratios, with $95 \%$ confidence intervals for all women, premenopause and postmenopause from multivariate logistic regression model of total fat, animal fat, vegetable fat, total SFA, total MUFA, total PUFA and cholesterol on women with and without breast cancer (cases, $n=473$; controls, $n=501$ )

are activated by oleate [50]. Therefore, an association has been recently highlighted between SCD1 activity, MUFA, and tumor growth [51]. Another investigation in postmenopausal women reported that oleic acid levels might have a role in breast cancer development [52].

In the present investigation, higher PUFA intake was related to $\mathrm{BC}$ risk in women with menopause. Limited studies have examined the link between PUFA intake and $\mathrm{BC}$ risk stratified by menopausal status. However, in the Malmo Diet and Cancer study, Wirfalt. et al. reported a positive association between PUFA intake and BC development in postmenopausal women [10]. Also, one study suggested that higher PUFA (linoleic acid) intake might increase BC risk [48]. Furthermore, dietary intake of PUFA commonly includes high proportions of linoleic acid, which is a biosynthetic precursor of prostaglandin [53]. Arachidonic fatty acids and prostaglandin E2 could increase estrogen synthesis by inducing aromatase enzymes activity, which might affect cancer development [54]. Aromatase catalyzes the conversion of androgens to estrogens and vice versa [55]. Estradiol fatty acid esters can be accumulated in fat tissues at high levels [56]. The high levels of estradiol in the mammary tissues can induce estrogen receptor (ER) expression and influence cancer cell behavior [57]. There is some evidence that estrogen induces mammary cell proliferation by controlling the expression of some related genes [58, 59]. Moreover, linoleic acid has a role in T47D growth control. This effect is performed by alteration in the G13a G protein, estrogen receptor (ERa), or p38 MAP kinase gene expression [60, 61]. Also, Murillo-Ortiz et al. stated that increased levels of circulating estradiol could increase the risk of HR-positive BC in postmenopausal Mexican women [62]. Lowering serum estradiol levels by dietary prevention may still offer an approach to $\mathrm{BC}$ prevention [63].

Different associations found in pre- and postmenopausal women might be explained by differences in body fat percentage. As in this study, the hypothesis of associations between body fat and BC could not be approved in premenopausal women. Likewise, Zhao et al. in a study in premenopausal women reported that reduced expression of RPS6KB1, ESR1, and GATA3 in breast adipose tissue plays a role to decrease the risk of breast cancer [64]. Other researchers also concluded that altered expression of some genes (RRM2, SPP1, MMP9, Arf1) could be involved in increased cell proliferation of adipose tissue in breast cancer risks [65, 66]. However, in postmenopausal women, adipose fat is the essential source of circulating estrogen [63,67]. In one previous study, dietary fat increased $\mathrm{BC}$ risk only in postmenopausal women [68]. Nonetheless, in some studies, there 
was no positive association between total fat or animal fat intake with estrogen levels in postmenopausal women $[69,70]$. Further studies are recommended to elucidate the exact mechanisms.

\section{Study strengths and limitations}

This investigation had some strengths. A quite big sample size, using standard questionnaires, performing a categorized analysis by menopausal status, and considering several confounding factors were some strengths. Prior studies found animal fat adversely affects BC risk in only premenopausal women; however, the current study found this association in postmenopausal women.

This study had some limitations. First, this was a casecontrol study, and the selection or recall bias could have affected the results. Second, the possibility of under- and over-reporting of either energy intake or special food groups and recall bias exists when using the semiquantitative FFQ. Third, although FFQs are often used to categorize participants' intakes rather than meticulous measurement of nutrient intake, a degree of gross misclassification is inevitable. Fourth, $\mathrm{BC}$ was not ruled out in controls. Fifth, the current study could not assess the hormonal receptors status and no information was available regarding breast cancer stage or grade.

\section{Conclusions}

There was a direct association between total dietary fat and subtypes of fat intake with the risk of BC development particularly in women with menopause. This observational study provides support for the importance of dietary fat intake in increasing the risk of breast cancer. Therefore, the amount of dietary total fat as well as fatty acids should be recommended with caution to reduce the risk of $\mathrm{BC}$. More intervention studies considering the effect of dietary fats on cell growth considering different subgroups of estrogen receptors are required.

\section{Abbreviations}

BC: Breast cancer; BMI: Body Mass Index; DHA: Docosahexaenoic acid; EPA: Eicosapentaenoic acid; FFQ: food frequency questionnaire; GPAQ: Global Physical Activity Questionnaire; kcal/d: kilocalories per day; MET-minutes/ weeks: Metabolic equivalent minutes per week; MUFA: Monounsaturated fatty acids; OR: Odds ratio; PUFA: Polyunsaturated fatty acids; SDs: standard deviations; SFAs: Saturated fatty acids; USDA: United States Department of Agriculture; WHO: World health organization

\section{Supplementary information}

The online version contains supplementary material available at https://doi. org/10.1186/s12944-021-01557-y.

\section{Additional file 1}

\section{Acknowledgements}

We would like to express our special thanks to participation of the study subjects, without whom the study would not have been possible.

\section{Authors' contributions}

MM drafted the initial version. BS and FT participated in the study design, analysis and drafted the initial version. BS implemented comments and suggestions of the co-authors. ASA contributed in data analysis and critical reading. KZ contributed in conception, design and data analysis. All authors reviewed the final version of the manuscript. KZ supervised the study.

Funding

Not applicable.

\section{Availability of data and materials}

The datasets generated and/or analyzed during the current study will be made available by request from the corresponding author.

\section{Declarations}

Ethics approval and consent to participate

This study was conducted according to the guidelines laid down in the Declaration of Helsinki and all procedures involving human subjects/patients were approved by Tehran University of Medical Sciences. A written informed consent was obtained from all patients. The study protocol was approved by the Bioethics Committee of Tehran University of Medical Sciences, Tehran, Iran (Ethics code: 93-03-51-27113).

\section{Consent for publication}

Not applicable.

\section{Competing interests}

None of the authors declared any conflicts of interest.

\section{Author details}

${ }^{1}$ Cancer Research Center, Cancer Institute of Iran, Tehran University of Medical Sciences, Tehran, Iran. ${ }^{2}$ Nutrition and Food Security Research Center, Shahid Sadoughi University of Medical Sciences, Yazd, Iran. ${ }^{3}$ Department of Nutrition, School of Public Health, Shahid Sadoughi University of Medical Sciences, Yazd, Iran. ${ }^{4}$ Department of Community Nutrition, School of Nutritional Sciences and Dietetics, Tehran University of Medical Sciences, Tehran, Iran. ${ }^{5}$ Cancer Biology Research Center, Cancer Institute of Iran, Tehran University of Medical Sciences, I.R., Tehran, Iran. ${ }^{6}$ Breast Diseases Research Center, Cancer Institute of Iran, Tehran University of Medical Sciences, I.R. Tehran, Iran. ${ }^{7}$ Cancer Research Center, Cancer Institute of Iran, Tehran University of Medical Sciences, P.O.Box 13145158, I.R., Tehran, Iran.

Received: 6 May 2021 Accepted: 14 September 2021

Published online: 17 October 2021

\section{References}

1. Akbari A, Razzaghi Z, Homaee F, Khayamzadeh M, Movahedi M, Akbari ME. Parity and breastfeeding are preventive measures against breast cancer in Iranian women. Breast cancer. 2011;18(1):51-5.

2. Bray F, Ferlay J, Soerjomataram I, Siegel RL, Torre LA, Jemal A. Global cancer statistics 2018: GLOBOCAN estimates of incidence and mortality worldwide for 36 cancers in 185 countries. Cancer J Clin. 2018;68(6):394-424.

3. Cancer IAfRo, World Health Organization. estimated breast cancer incidense 2020 [Available from: .

4. Chajès $V$, Assi $N$, Biessy $C$, Ferrari $P$, Rinaldi $S$, Slimani $N$, et al. A prospective evaluation of plasma phospholipid fatty acids and breast cancer risk in the EPIC study. Ann Oncol. 2017:28(11):2836-42.

5. Ghosn B, Benisi-Kohansal S, Ebrahimpour-Koujan S, Azadbakht L, Esmaillzadeh A. Association between healthy lifestyle score and breast cancer. Nutr J. 2020;19(1):1-11.

6. Smith-Warner SA, Spiegelman D, Adami HO, Beeson WL, Van Den Brandt PA, Folsom AR, et al. Types of dietary fat and breast cancer: a pooled analysis of cohort studies. International journal of cancer. 2001;92(5):767-74.

7. Psaltopoulou T, Kosti RI, Haidopoulos D, Dimopoulos M, Panagiotakos DB. Olive oil intake is inversely related to cancer prevalence: a systematic review and a meta-analysis of 13800 patients and 23340 controls in 19 observational studies. Lipids Health Dis. 2011;10(1):127.

8. Howe GR, Hirohata T, Hislop TG, Iscovich JM, Yuan J-M, Katsouyanni K, et al. Dietary factors and risk of breast cancer: combined analysis of 12 
case — control studies. JNCl: Journal of the National Cancer Institute. 1990; 82(7):561-9.

9. Richardson S, Vincenzi ID, Pujol H, Gerber M. Alcohol consumption in a case-control study of breast cancer in southern France. International journal of cancer. 1989;44(1):84-9.

10. Wirfält E, Mattisson I, Gullberg B, Johansson U, Olsson H, Berglund G. Postmenopausal breast cancer is associated with high intakes of $\omega 6$ fatty acids (Sweden). Cancer Causes Control. 2002;13(10):883-93.

11. Wakai K, Dillon DS, Ohno Y, Prihartono J, Budiningsih S, Ramli M, et al. Fat intake and breast cancer risk in an area where fat intake is low: a casecontrol study in Indonesia. Int J Epidemiol. 2000;29(1):20-8.

12. Tjønneland A, Christensen J, Olsen A, Stripp C, Thomsen BL, Overvad K, et al. Alcohol intake and breast cancer risk: the European Prospective Investigation into Cancer and Nutrition (EPIC). Cancer Causes Control. 2007; 18(4):361-73.

13. Boyd N, Stone J, Vogt K, Connelly B, Martin L, Minkin S. Dietary fat and breast cancer risk revisited: a meta-analysis of the published literature. British journal of cancer. 2003;89(9):1672-85.

14. Goodstine SL, Zheng T, Holford TR, Ward BA, Carter D, Owens PH, Mayne ST. Dietary $(n-3) /(n-6)$ fatty acid ratio: possible relationship to premenopausal but not postmenopausal breast cancer risk in US women. J Nutr. 2003;133(5):1409-14.

15. Maillard $V$, Bougnoux $P$, Ferrari $P$, Jourdan $M L$, Pinault $M$, Lavillonnière $F$, Body $\mathrm{G}$, Le Floch $\mathrm{O}$, Chajès V. N-3 and N-6 fatty acids in breast adipose tissue and relative risk of breast cancer in a case-control study in Tours, France. Int J Cancer. 2002;98(1):78-83.

16. Ouldamer L, Goupille C, Vilde A, Arbion F, Body G, Chevalier S, Cottier JP, Bougnoux P. N-3 Polyunsaturated fatty acids of marine origin and multifocality in human breast cancer. PloS one, 2016. 11(1).

17. van den Brandt PA, van't Veer P, Goldbohm RA, Dorant E, Volovics A, Hermus RJ, Sturmans F. A prospective cohort study on dietary fat and the risk of postmenopausal breast cancer. Cancer research. 1993;53(1): 75-82.

18. Löf M, Sandin S, Lagiou P, Hilakivi-Clarke L, Trichopoulos D, Adami H, Weiderpass E. Dietary fat and breast cancer risk in the Swedish women's lifestyle and health cohort. British journal of cancer. 2007;97(11):1570-6.

19. Gago-Dominguez M, Yuan J, Sun C, Lee H, Yu M. Opposing effects of dietary n-3 and n-6 fatty acids on mammary carcinogenesis: The Singapore Chinese Health Study. British journal of cancer. 2003;89(9):1686-92.

20. Saadatian-Elahi M, Norat T, Goudable J, Riboli E. Biomarkers of dietary fatty acid intake and the risk of breast cancer: A meta-analysis. International journal of cancer. 2004;111(4):584-91.

21. Sczaniecka AK, Brasky TM, Lampe JW, Patterson RE, White E. Dietary intake of specific fatty acids and breast cancer risk among postmenopausal women in the VITAL cohort. Nutrition cancer. 2012;64(8):1131-42.

22. Khankari NK, Bradshaw PT, Steck SE, He K, Olshan AF, Shen J, et al., Dietary intake of fish, polyunsaturated fatty acids, and survival after breast cancer: A population-based follow-up study on Long Island, New York. Cancer, 2015. 121(13): p. 2244-2252

23. Farvid MS, Cho E, Chen WY, Eliassen AH, Willett WC. Premenopausal dietary fat in relation to pre-and post-menopausal breast cancer. Breast cancer research treatment. 2014;145(1):255-65.

24. Lee H, Lee J, Gourley L, Duffy S, Day N, Estève J, Dietary effects on breastcancer risk in Singapore. The lancet, 1991. 337(8751): p. 1197-1200.

25. Cho E, Spiegelman D, Hunter DJ, Chen WY, Stampfer MJ, Colditz GA, Willett WC. Premenopausal fat intake and risk of breast cancer. J Natl Cancer Inst. 2003;95(14):1079-85.

26. Abdollahi M, MOHAMMADI NF, Houshiarrad A, GHAFARPOUR M, Ghodsi D, Kalantari N, Socio-economic differences in dietary intakes: the comprehensive study on household food consumption patterns and nutritional status of IR Iran. 2014.

27. Mirmiran P, Esfahani FH, Mehrabi Y, Hedayati M, Azizi F. Reliability and relative validity of an FFQ for nutrients in the Tehran lipid and glucose study. Public Health Nutr. 2010;13(5):654-62.

28. Esfahani FH, Asghari G, Mirmiran P, Azizi F. Reproducibility and relative validity of food group intake in a food frequency questionnaire developed for the Tehran Lipid and Glucose Study. Journal of epidemiology. 2010; 20(2):150-8.

29. Ghaffarpour M, Houshiar-Rad A, Kianfar H. The manual for household measures, cooking yields factors and edible portion of foods. Tehran: Nashre Olume Keshavarzy. 1999;7(213):42-58.
30. Haytowitz D, Lemar L, Pehrsson P, Exler J, Patterson K, Thomas R, et al. USDA national nutrient database for standard reference, release 24. Washington, DC, USA: US Department of Agriculture; 2011.

31. Armstrong T, Bull F. Development of the world health organization global physical activity questionnaire (GPAQ). J Public Health. 2006;14(2):66-70.

32. Organization WH, Global physical activity questionnaire (GPAQ) analysis quide. 2012, Geneva.

33. Willett $\mathrm{W}$, Implications of total energy intake for epidemiologic analyses. Nutritional epidemiology, 1998: p. 273-301.

34. Holmes MD, Hunter DJ, Colditz GA, Stampfer MJ, Hankinson SE, Speizer FE, Rosner B, Willett WC. Association of dietary intake of fat and fatty acids with risk of breast cancer. Jama. 1999;281(10):914-20.

35. Cao Y, Hou L, Wang W. Dietary total fat and fatty acids intake, serum fatty acids and risk of breast cancer: A meta-analysis of prospective cohort studies. International journal of cancer. 2016;138(8):1894-904.

36. Alexander DD, Morimoto LM, Mink PJ, Lowe KA. Summary and metaanalysis of prospective studies of animal fat intake and breast cancer. Nutr Res Rev. 2010;23(1):169-79.

37. Bertrand KA, Burian RA, Eliassen AH, Willett WC, Tamimi RM. Adolescent intake of animal fat and red meat in relation to premenopausal mammographic density. Breast cancer research treatment. 2016;155(2):385-93.

38. Öztürk MA, Keçeci M, Kömoğlu S, Eryllmaz M, Sertbaș Y, Sertbaș M, Özdemir A. Association Between Hyperlipidemia and Mammographic Breast Density in Post-menopausal Women. Southern Clinics of Istanbul Eurasia, 2018. 29(2)

39. Toniolo P, Riboli E, Protta F, Charrel M, Cappa AP. Calorie-providing nutrients and risk of breast cancer. JNCl: Journal of the National Cancer Institute. 1989;81(4):278-86

40. Saadatian-Elahi M, Toniolo P, Ferrari P, Goudable J, Akhmedkhanov A, Zeleniuch-Jacquotte A, Riboli E, Serum fatty acids and risk of breast cancer in a nested case-control study of the New York University Women's Health Study. Cancer Epidemiology and Prevention Biomarkers, 2002. 11(11): p. 13531360.

41. Hunter DJ, Spiegelman D, Adami H-O, Beeson L, Van Den Brandt PA, Folsom AR, et al. Cohort studies of fat intake and the risk of breast cancer-a pooled analysis. N Engl J Med. 1996;334(6):356-61.

42. De Souza CT, Araujo EP, Bordin S, Ashimine R, Zollner RL, Boschero AC, Saad $\mathrm{MJ}$, Velloso LCA. Consumption of a fat-rich diet activates a proinflammatory response and induces insulin resistance in the hypothalamus. Endocrinology. 2005;146(10):4192-9.

43. Orgel E, Mittelman SD. The links between insulin resistance, diabetes, and cancer. Curr Diabetes Rep. 2013;13(2):213-22.

44. Howe LR, Subbaramaiah K, Hudis CA, Dannenberg AJ. Molecular pathways: adipose inflammation as a mediator of obesity-associated cancer. Clinical cancer research. 2013;19(22):6074-83.

45. Ye J, Jia J, Dong S, Zhang C, Yu S, Li L, et al. Circulating adiponectin levels and the risk of breast cancer: a meta-analysis. European journal of cancer prevention. 2014;23(3):158-65.

46. Hirko KA, Chai B, Spiegelman D, Campos H, Farvid MS, Hankinson SE, Willett WC, Eliassen AH. Erythrocyte membrane fatty acids and breast cancer risk: a prospective analysis in the nurses' health study II. International journal of cancer. 2018;142(6):1116-29.

47. Wang J, John EM, Horn-Ross PL, Ingles SA. Dietary fat, cooking fat, and breast cancer risk in a multiethnic population. Nutrition cancer. 2008;60(4): 492-504.

48. Wolk A, Bergström R, Hunter D, Willett W, Ljung H, Holmberg L, Bergkvist L, Bruce $\AA$, Adami H-O. A prospective study of association of monounsaturated fat and other types of fat with risk of breast cancer. Arch Intern Med. 1998;158(1):41-5.

49. Dierssen-Sotos T, Gómez-Acebo I, Palazuelos C, Gracia-Lavedan E, PérezGómez B, Oribe M, et al., Fatty acid intake and breast cancer in the Spanish multicase-control study on cancer (MCC-Spain). European journal of nutrition, 2019: p. 1-9.

50. Hilvo M, Gade S, Hyötyläinen T, Nekljudova V, Seppänen-Laakso T, Sysi-Aho $\mathrm{M}$, et al. Monounsaturated fatty acids in serum triacylglycerols are associated with response to neoadjuvant chemotherapy in breast cancer patients. Int J Cancer. 2014;134(7):1725-33.

51. Scaglia N, Chisholm JW, Igal RA. Inhibition of stearoylCoA desaturase-1 inactivates acetyl-CoA carboxylase and impairs proliferation in cancer cells: role of AMPK. PloS one. 2009;4(8):e6812. 
52. Pala V, Krogh V, Muti P, Chajès V, Riboli E, Micheli A, Saadatian M, Sieri S, Berrino F. Erythrocyte membrane fatty acids and subsequent breast cancer: a prospective Italian study. J Natl Cancer Inst. 2001;93(14):1088-95.

53. Aylsworth CF, Jone C, Trosko JE, Meites J, Welsch CW, Promotion of 7, 12dimethylbenz [a] anthracene-induced mammary tumorigenesis by high dietary fat in the rat: possible role of intercellular communication. Journal of the National Cancer Institute, 1984. 72(3): p. 637-645.

54. Nindrea RD, Aryandono T, Lazuardi L, Dwiprahasto I. Association of dietary intake ratio of $n-3 / n-6$ polyunsaturated fatty acids with breast cancer risk in Western and Asian countries: A meta-analysis. Asian Pacific journal of cancer prevention: APJCP. 2019:20(5):1321.

55. Cleary MP, Grossmann ME. Obesity and breast cancer: the estrogen connection. Endocrinology. 2009;150(6):2537-42.

56. Larner JM, Shackleton C, Roitman E, Schwartz PE, Hochberg RB. Measurement of estradiol-17-fatty acid esters in human tissues. The Journal of Clinical Endocrinology Metabolism. 1992;75(1):195-200.

57. Dunneram Y, Greenwood DC, Cade JE, Diet, menopause and the risk of ovarian, endometrial and breast cancer. Proceedings of the Nutrition Society, 2019. 78(3): p. 438-448.

58. Kachhap SK, Dange $P$, Ghosh SN. Effect of $\omega-6$ polyunsaturated fatty acid (linoleic acid) on BRCA1 gene expression in MCF-7 cell line. Cancer letters. 2000;154(2):115-20.

59. Nelson KG, Takahashi T, Lee DC, Luetteke NC, Bossert NL, Ross K, Eitzman BE, McLachlan J. Transforming growth factor-alpha is a potential mediator of estrogen action in the mouse uterus. Endocrinology. 1992;131(4):165764.

60. Reyes N, Reyes I, Tiwari R, Geliebter J. Effect of linoleic acid on proliferation and gene expression in the breast cancer cell line T47D. Cancer letters. 2004;209(1):25-35.

61. Natarajan R, Nadler J. Role of lipoxygenases in breast cancer. Front Biosci. 1998;3(81):8

62. Murillo-Ortiz B, Martínez-Garza S, Landeros VC, Velázquez GC, Garcia DS. Effect of reduced dietary fat on estradiol, adiponectin, and IGF-1 levels in postmenopausal women with breast cancer. Breast Cancer: Targets Therapy. 2017;9:359.

63. Wu AH, Pike MC, Stram DO. Meta-analysis: dietary fat intake, serum estrogen levels, and the risk of breast cancer. J Natl Cancer Inst. 1999;91 (6):529-34.

64. Zhao H, Wang J, Fang D, Lee O, Chatterton R, Stearns V, Khan S, Bulun S. Adiposity results in metabolic and inflammation differences in premenopausal and postmenopausal women consistent with the difference in breast cancer risk. Horm Cancer. 2018;9(4):229-39.

65. Wang G, Xu J, Zhao J, Yin W, Liu D, Chen W, Hou SX. Arf1-mediated lipid metabolism sustains cancer cells and its ablation induces anti-tumor immune responses in mice. Nature communications. 2020;11(1):1-16.

66. Sturtz LA, Deyarmin B, van Laar R, Yarina W, Shriver CD, Ellsworth RE. Gene expression differences in adipose tissue associated with breast tumorigenesis Adipocyte. 2014;3(2):107-14.

67. Guo W, Key TJ, Reeves GK. Adiposity and breast cancer risk in postmenopausal women: Results from the UK Biobank prospective cohort. International journal of cancer. 2018;143(5):1037-46.

68. Kushi LH, Potter JD, Bostick RM, Drinkard CR, Sellers TA, Gapstur SM, Cerhan $J R$, Folsom AR. Dietary fat and risk of breast cancer according to hormone receptor status. Cancer Epidemiology Prevention Biomarkers. 1995;4(1):11-9.

69. Holmes MD, Spiegelman D, Willett WC, Manson JE, Hunter DJ, Barbieri RL, Colditz GA, Hankinson SE. Dietary fat intake and endogenous sex steroid hormone levels in postmenopausal women. Journal of clinical oncology. 2000;18(21):3668-76.

70. Kim EH, Willett WC, Colditz GA, Hankinson SE, Stampfer MJ, Hunter DJ, Rosner B, Holmes MD. Dietary fat and risk of postmenopausal breast cancer in a 20-year follow-up. Am J Epidemiol. 2006;164(10):990-7.

\section{Publisher's Note}

Springer Nature remains neutral with regard to jurisdictional claims in published maps and institutional affiliations.

Ready to submit your research? Choose BMC and benefit from:

- fast, convenient online submission

- thorough peer review by experienced researchers in your field

- rapid publication on acceptance

- support for research data, including large and complex data types

- gold Open Access which fosters wider collaboration and increased citations

- maximum visibility for your research: over $100 \mathrm{M}$ website views per year

At BMC, research is always in progress.

Learn more biomedcentral.com/submissions 